\title{
Variable population exposure and distributed travel speeds in least-cost tsunami evacuation modelling
}

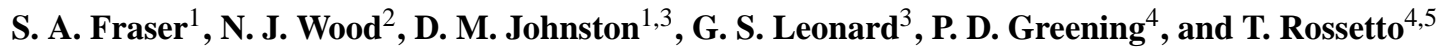 \\ ${ }^{1}$ GNS Science/Massey University Joint Centre for Disaster Research, Massey University (Wellington Campus), P.O. Box 756, \\ 6140 Wellington, New Zealand \\ ${ }^{2}$ United States Geological Survey, 2130 SW 5th Avenue, Portland, OR 97201, USA \\ ${ }^{3}$ GNS Science, P.O. Box 30 368, 5010 Lower Hutt, New Zealand \\ ${ }^{4}$ Department of Civil, Environmental and Geomatic Engineering, University College London, Gower Street, \\ London, WC1E 6BT, UK \\ ${ }^{5}$ The Earthquake and People Interaction Centre (EPICentre), University College London, Gower Street, \\ London, WC1E 6BT, UK
}

Correspondence to: S. A. Fraser (s.a.fraser@massey.ac.nz)

Received: 23 April 2014 - Published in Nat. Hazards Earth Syst. Sci. Discuss.: 10 June 2014

Revised: - - Accepted: 6 October 2014 - Published: 17 November 2014

\begin{abstract}
Evacuation of the population from a tsunami hazard zone is vital to reduce life-loss due to inundation. Geospatial least-cost distance modelling provides one approach to assessing tsunami evacuation potential. Previous models have generally used two static exposure scenarios and fixed travel speeds to represent population movement. Some analyses have assumed immediate departure or a common evacuation departure time for all exposed population. Here, a method is proposed to incorporate time-variable exposure, distributed travel speeds, and uncertain evacuation departure time into an existing anisotropic least-cost path distance framework. The method is demonstrated for hypothetical local-source tsunami evacuation in Napier City, Hawke's Bay, New Zealand. There is significant diurnal variation in pedestrian evacuation potential at the suburb level, although the total number of people unable to evacuate is stable across all scenarios. Whilst some fixed travel speeds approximate a distributed speed approach, others may overestimate evacuation potential. The impact of evacuation departure time is a significant contributor to total evacuation time. This method improves least-cost modelling of evacuation dynamics for evacuation planning, casualty modelling, and development of emergency response training scenarios. However, it requires detailed exposure data, which may preclude its use in many situations.
\end{abstract}

\section{Introduction}

Local-source (or near-field) tsunami can cause loss of life due to onshore inundation within minutes after a source event. Prompt evacuation of the hazard zone maximises a person's chance of surviving tsunami inundation. Well-planned routes and refuges facilitate evacuation by minimising travel time to safety and maximising the number of people reaching safe refuge. Evacuation modelling is an important tool for estimating exposure to the hazard and the time required to evacuate the hazard zone.

Least-cost distance (LCD) analysis is an established method for tsunami evacuation modelling (Graehl and Dengler, 2008; Post et al., 2009; Scheer et al., 2011; Wood and Schmidtlein, 2012, 2013; González-Riancho et al., 2013). LCD analysis is a Geographic Information System (GIS)-based method that computes the minimum cost of travel (generally expended energy or time) between specified source and destination cells in a raster domain (i.e. a cellbased grid). Travel speed values can be applied to the cost distance surface to generate a time surface representing the time to travel from source to destination. Travel time maps enable emergency managers to visualise spatial variation in evacuation time (Wood and Schmidtlein, 2012). Comparison of travel time to wave arrival in tsunami inundation scenarios enables identification of areas that cannot be evacuated 


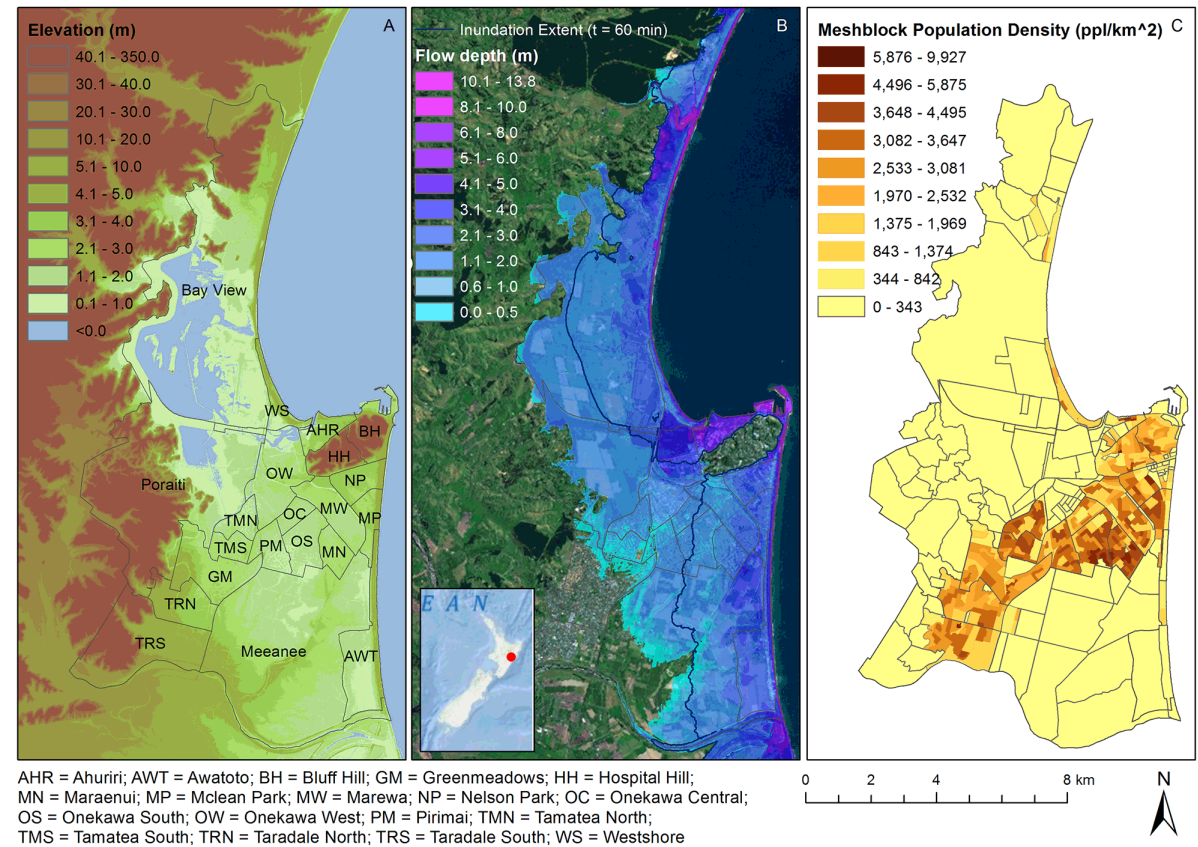

Figure 1. (a) Study area topography and locations of suburbs in Napier Territorial Authority. (b) Simulated flow depth due to the maximum credible local-source subduction earthquake and inundation extent at $60 \mathrm{~min}$ after rupture (Fraser et al., 2014). Inset shows the position of Napier in the national context. (c) Meshblock boundaries and 2013 estimate of URP density for each meshblock (for clarity, smaller meshblocks are shown without boundaries). URP density is classified using Natural Breaks (Jenks).

before wave arrival. Combining travel time and population exposure data gives an indication of the number of people potentially unable to evacuate in the available time, which facilitates planning of additional evacuation and emergency response solutions.

In order to simulate evacuation processes at the community scale, a model must represent the physical environment, spatial extent and timing of the hazard, population exposure, and human behaviour with respect to evacuation decisions and timing. To date, LCD models have been tested for sensitivity to elevation and landcover data: Wood and Schmidtlein (2012) concluded that the use of anisotropic path distance provides a more realistic cost distance estimate than the previous use of isotropic cost distance. Post et al. (2009) applied increased complexity to LCD analysis by including network capacity and evacuee density as modifiers of travel cost. Three other evacuation factors - population exposure, departure time and travel speed - have been consistently applied as static values in previous LCD approaches, which may not represent the potential variability in these factors.

The objective of this paper is to demonstrate a method for introducing variability in population exposure scenarios, evacuation departure times and travel speeds into an anisotropic, least-cost, path distance model of pedestrian evacuation potential. The importance of traffic modelling, network capacity issues, evacuee interactions and disruption to evacuation routes due to earthquake damage are recognised; however, in order to focus on modelling the variability in exposure, departure and travel phases, these aspects have not be incorporated into the demonstrated process. Population-time profiles are developed to model the distribution of residents and visitors at any time of day, for a weekday or weekend, in any month of the year. Incorporating distributions to model departure time and evacuation travel speed better reflects evacuee behaviour in a real-world evacuation than current GIS-based approaches to mapping evacuation potential. The ability to model temporally variable exposure facilitates derivation of hazard exposure, evacuation demands and optimal evacuation routes and refuges for specific scenarios. Emergency managers can use multiple exposure scenarios to develop evacuation training exercises, evacuation planning and casualty estimation.

\section{Study area}

To demonstrate the proposed method, we focus on the coastal community of Napier, Hawke's Bay, New Zealand, which faces a significant local-source subduction zone tsunami hazard (Power, 2013; Fraser et al., 2014). Napier is a city of almost 60000 people located on largely flat, low-lying topography (Fig. 1a), on the east coast of New Zealand's North Island. A single numerically simulated inundation scenario is used to demonstrate the proposed evacuation modelling method. The scenario is a tsunami generated by the maximum credible $M_{\mathrm{W}} 9.0$ local-source earthquake on the 
Hikurangi subduction zone (Fraser et al., 2014). Simulated wave arrival at shore occurs $38 \mathrm{~min}$ after rupture and inundation reaches its maximum extent ( $>4 \mathrm{~km}$ inland) $32 \mathrm{~min}$ later. Flow depths exceed $8 \mathrm{~m}$ in the first $100 \mathrm{~m}$ onshore and generally up to $3 \mathrm{~m}$ further than $1 \mathrm{~km}$ inland (Fig. 1b). The simulated maximum credible inundation zone is taken to be the tsunami hazard zone and is referred to as such in the rest of this paper.

Bluff Hill (maximum elevation $>100 \mathrm{~m}$ ) provides the only area of high ground at the coast for refuge, although other areas of high ground exist further inland of the hazard zone (Fig. 1a). The existing building stock is overwhelmingly 1-2 storey light timber ( $92 \%)$, with a small proportion of 1-2 storey reinforced concrete $(\mathrm{RC} ; 3 \%)$ and $1-2$ storey concrete masonry (3\%) (Cousins, 2009). Approximately 60 buildings $(0.05 \%)$ are three storeys or more in height, $40 \%$ of which are of RC construction. The second storey may provide sufficient height for safe refuge in inland areas of the city but this is less likely in the $1 \mathrm{~km}$ closest to shore. The probability of moderate to major structural damage due to tsunami loading in the maximum credible tsunami is greater than $80 \%$ for RC and greater than $90 \%$ for timber structures in the maximum credible tsunami (Fraser et al., 2014). Structural assessments are yet to confirm the tsunamiresistance of multi-storey buildings in the city. Therefore, this study does not include any existing buildings as potential refuges when considering pedestrian evacuation potential.

\section{Methodology: least-cost path distance approach to determining pedestrian evacuation potential}

The steps implemented in this methodology are described in this section. First, an anisotropic least-cost path distance analysis is set up, using physical data and hazard data for a chosen area. Second, several time-variable population exposure scenarios are created using building locations and various population statistics. Third, estimates of evacuation departure time and pedestrian travel speed are combined with the two prior components, to produce an overall view of pedestrian evacuation potential for the population in question.

\subsection{Anisotropic least-cost path distance analysis}

LCD analysis is conducted in ESRI ArcGIS 10.1 following the anisotropic least-cost path distance method of Wood and Schmidtlein (2012). Least-cost path distance determines the minimum path distance from every cell in the hazard zone to the nearest point of safety outside the hazard zone. The hazard zone and tsunami arrival time are identified by numerical inundation modelling (Fraser et al., 2014, Fig. 1b). Use of arrival time at shore provides a conservative estimate of arrival time for most locations in the hazard zone because there is additional time before inundation reaches its maximum inland extent.

The anisotropic approach accounts for the cost associated with direction of travel over sloping terrain of different surface type. High-resolution ground surface Light Detection and Ranging (LiDAR) data are used to generate a digital elevation model (DEM) at $2 \mathrm{~m}$ horizontal resolution. Most short-span bridges in Napier are represented in the LiDAR data but manual augmentation is required to include the deck elevation of longer span bridges. These would otherwise be omitted, resulting in a road being erroneously intersected by steep terrain, artificially increasing the path distance value on that route. Tobler's hiking functions (Tobler, 1993) are used to convert directional slope (derived from the DEM) into a travel speed cost, interpreting travel in a downhill direction as a benefit and uphill travel as an additional travel cost.

Land cover data are compiled from aggregated polygon data (Ministry for the Environment, 2009) representing ground surface cover. The aggregated data do not include roads, waterways or buildings, so additional polygon and polyline data are combined into a single comprehensive land cover raster. Land cover is represented in the LCD analysis by using a Speed Conservation Value (SCV), which is a speed-reduction factor representing the ease of travel over that land cover (Wood and Schmidtlein, 2012). Any cell representing a road is assigned $\mathrm{SCV}=1.0$ (having no impedance on travel speed) and any cell representing a water body or building is defined as impassable, to ensure evacuation routing around these features. Other land cover categories in the study included: Dirt road $(\mathrm{SCV}=0.9091)$, Light brush (0.8333), Heavy brush (0.6667), Hard sand and Swampy bog (both 0.5556).

\subsection{Time-variable population exposure}

Estimates of population located within a hazard zone (the exposed population) are required to provide evacuees' starting locations. Exposure is typically derived directly from census data, which primarily indicates night-time population distributions. Day-time exposure can be estimated by augmenting census data with additional information, such as maximum building capacity determined by floor area (Cousins, 2009), employment records (Wood and Schmidtlein, 2012), or average rates of schooling, employment and numbers of cars at home (Southworth, 1991). In addition to the location of residents who are at home or a workplace, exposure models should include people in institutional facilities, in transit, working outdoors or undertaking leisure activities. Models should also include visitors and commuting patterns. Previous LCD tsunami evacuation models have used up to two exposure scenarios or the maximum exposure, derived from a night-time scenario and a day-time scenario. Random distribution of population has been used to represent exposure uncertainty in stochastic agent-based simulations (Mas et al., 2012). Recent progress has been 

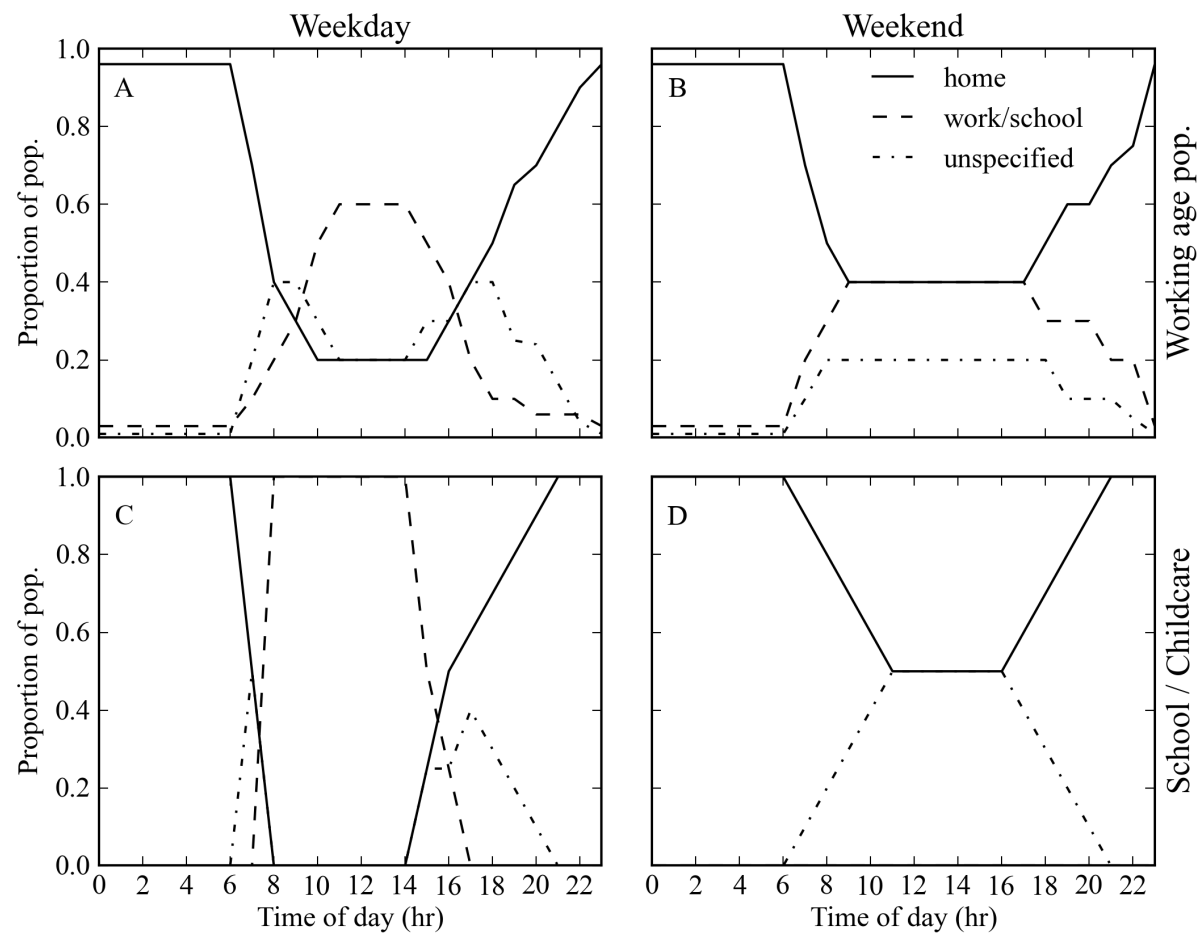

Figure 2. Population-time profiles to distribute working-age adults (a, b) and children (c, d) to home, work/school and unspecified locations. Profiles are shown for a weekday $(\mathbf{a}, \mathbf{c})$ and weekend $(\mathbf{b}, \mathbf{d})$.

made in modellingpopulation dynamics by assigning population-time profiles to different types of locations (Cockings et al., 2010) and by using transport data in short time-slices to estimate diurnal changes in spatio-temporal population distribution (Kobayashi et al., 2011). However, such time profiles have yet to be applied in tsunami evacuation modelling.

In this study, total night-time population is obtained from 2006 census Usually Resident Population (URP) data at meshblock-resolution and adjusted to 2013 values based on local population projections (Ministry of Education, 2012a; Statistics New Zealand, 2006). A meshblock is a New Zealand cadastral entity, generally covering less than $1.0-4.4 \mathrm{~km}^{2}$ in Napier (Fig. 1c). Five population groups are defined on the basis of predominant diurnal activity and age: school/childcare, working-age adults, independent elderly, dependent elderly and visitors. Whilst it is recognised that physical and intellectual disabilities can affect evacuation decision-making and mobility in evacuation, resulting in an increase in required evacuation time, it is not possible to determine the magnitude of impact of each type of disability registered. By using age to determine mobility impairment, we have captured the majority of mobility impairment in the population. However, this represents an important area of further study.

The groups are used in the model to assign exposure locations and travel speed distributions. Employment data, education rolls and care facility capacities are used to define the proportion of URP in each population group. These data are site specific; data relevant to the local area should be sought for analyses of other areas.

Population-time profiles are used to define the certain proportion of each group at different types of location according to the month, day and time of the chosen exposure scenario (Fig. 2). The profiles define three types of location as: home or temporary accommodation (also includes elderly care facilities), work or school/childcare, and unspecified location to represent people in transit or outdoors. Time profiles are developed using employment shift patterns (Statistics New Zealand, 2006), regional commuting patterns ${ }^{1}$, US diurnal activity patterns (Klepeis et al., 2001), and local knowledge of school hours and peak commuting hours. Building locations and occupancy type are obtained from a regional exposure model developed for the national asset and loss model, RiskScape (Cousins, 2009). Two population-time profiles are developed for each group, one for a weekday and one for a weekend, to account for differing diurnal activity on working and non-working days. To include seasonal distribution of tourists in the exposed population, regional and local monthly visitor data are converted to an average daily number of visitors for each month. A description of the development of each population group and the respective population-time profile follows in Sects. 3.2.2-3.2.5.

\footnotetext{
${ }^{1}$ Source: Statistics New Zealand, customised report and licensed by Statistics NZ for re-use under the Creative Commons attribution 3.0 New Zealand license.
} 
Twelve exposure scenarios are generated using the timevariable exposure model, then analysed for evacuation demand. The scenarios (all given in local time) comprise: 02:00 weekday, 12:00 weekday and 12:00 weekend, repeated for February, May and November (high-, low- and mid-tourist season, respectively). February weekday 08:00 and 17:00 scenarios are generated to represent peak commuting times and January weekend 12:00 to demonstrate peak tourist numbers. This range of scenarios demonstrates the flexibility of the time-variable exposure model and assesses the influence of changing exposure on evacuation demand.

\subsubsection{Exposure distribution - methods applicable to all population groups}

The proportion of each population group assigned as being at home is combined into a single "residential population group". Each meshblock is assigned a residential population for that exposure scenario, according to the proportional contribution of the meshblock to total URP. The derived population of each meshblock is then distributed to randomly selected buildings in that meshblock, in a household group of variable size. Household group size is sampled from a weighted distribution of "number of household occupants": $36 \%$ of households in Hawke's Bay comprise two people, $25 \%$ have one person, $15 \%$ have three people and $13 \%$ have four (Statistics New Zealand, 2006). Distribution in a group enables a single travel speed to be assigned to the group, to represent the effect of household evacuation as a group.

To distribute the proportion of each population group assigned to an unspecified location, a spatially-weighted distribution is developed using a GIS weighted overlay algorithm. In a mixed-density mixed-use urban area, population distribution is unlikely to be entirely random because people spend a significant majority of their time in residential buildings (Klepeis et al., 2001; Leech et al., 2002) and are likely to otherwise congregate around commercial services and community facilities. Therefore, building density is used as a proxy to determine the locations of population who are not defined as being at a residence, workplace, school/childcare centre or carehome. Raster surfaces of (a) commercial-use building density and (b) non-commercial building density are calculated using the Kernel Point Density tool in ArcGIS 10.1. The two surfaces are combined using importance-weights of 70 and $30 \%$, respectively, subjectively defined to represent the relatively greater importance of commercial buildings for congregation of population, then reclassified to a combined weighting. In the combined raster, highly weighted cells reflect areas of highest building density, based on building footprint. The population is then distributed according to the weighted surface using a spatial analysis platform (Geospatial Modelling Environment; Beyer, 2012). This approach ensures that while each individual's location is random, the model contains realistic aggregations of population around commercial and public services and facilities in the city.

\subsubsection{Distribution of working-age adults}

Population assigned to a workplace is distributed to randomly selected commercial, industrial, or community-use buildings until the maximum person-capacity of the building is satisfied. Capacity is determined using the building floor area $\left(\mathrm{m}^{2}\right)$ and required floor area per person (Cousins, 2009). The proportion of this group assigned to residences and to unspecified locations is distributed according to the method in Sect. 3.2.1. The number of working-age adults (aged 18-65 years) is derived from census data (Statistics New Zealand, 2012a). All members of this group are assigned an adult unimpaired travel speed.

Employment statistics (Statistics New Zealand, see note 1) show that approximately $80 \%$ of this group are in employment (Napier City Council, 2013). Regional employment shift data show that $89 \%$ of working-age adults are in day-time employment (Statistics New Zealand). Therefore on a weekday, $60 \%$ of working-age adults are assigned to commercial or industrial buildings between 10:00-16:00 and $20 \%$ to unspecified locations to represent people working in outdoor locations or in transit while working (Fig. 2a). The remaining $20 \%$ are distributed to randomly selected residential buildings to represent those at home during the day (working and non-working population). In the hours 08:00-10:00 and 16:00-18:00, the proportion of people at unspecified locations peaks to represent commuting between residences and workplaces. There are no data available to inform the rate of movement of people at these times, so the population-time profiles curves are developed using expert judgement to assume movement to residential buildings during this time. Regional commuting data shows a net reduction of c. 7000 people in the working-age population during weekdays (assumed to be 08:00-17:00) due to the disparity in numbers of incoming and outgoing commuters. The net balance of commuters is expected to be much less on weekends, so the effect of commuters is only included on weekday. The weekend population-time profile assumes, using expert judgement, that $40 \%$ of working-age adults are at workplaces during the day, with $40 \%$ at home and $20 \%$ at unspecified locations (Fig. 2b). To account for night-shift workers in buildings, $2.5 \%$ of working-age adults are assigned to workplaces during evening hours and $0.5 \%$ of them are assigned to unspecified locations. The distribution of people working in evenings $(8 \%)$ and overnight $(3 \%)$ is based on employment shift data (Statistics New Zealand).

\subsubsection{Distribution of children to schools and childcare centres}

School rolls are obtained for the 34 schools and one tertiary college in Napier (Ministry of Education, 2012a). Attendance rolls for 64 childcare centres are obtained from the Ministry of Education (2012b). Where published roll data are not available for a centre, the mean attendance roll of all 
other centres is applied. The weekday distribution of children places $100 \%$ of children as assumed to be in school or childcare during 08:00-14:00, and at home during 21:00-07:00 (Fig. 2c). No data are available to inform the distribution of children between school or childcare centre, home and unspecified locations in the intervening hours, so this is subjectively assigned. The combined school and childcare roll (21 200) is greater than the 2013 adjusted population for age group 2-18 years (13933). The surplus is assumed to be schoolchildren commuting in from other territorial authorities and they are not included in exposure scenarios between 17:00-07:00.

To account for the total number of people on site, staff numbers are included in the exposure estimates of childcare facilities using a ratio of one staff member per ten children (Napier Kindergartens, 2012). In schools, the number of staff are not added to the school roll due to the large school population and lower ratio of staff to students. All people distributed to education sites are assigned child travel speed, due to the expectation that schools will evacuate in class groups, therefore have reduced speed. Currently, data are not available to elaborate on the effect of group evacuation on travel speed.

\subsubsection{Distribution of dependent and independent elderly}

The population at 17 elderly care facilities and retirement villages (1000 people) is defined as dependent elderly and assigned to the slowest travel speed group (elderly). There are an estimated 10000 people above 65 years who are considered for this analysis to reside at home, defined in this model as independent elderly. This group are considered to be more mobile than dependent elderly, so are assigned to the adult impaired travel speed group.

Both groups are part of the non-working population, assumed based on expert judgement to be located at home or care facility between 18:00-06:00 (Fig. 3a and b). Daytime location is assumed to be $60 \%$ at home/facility between 10:00-14:00 and $40 \%$ at unspecified locations. The distribution in the intermediate periods of time (07:00-09:00 and 15:00-17:00) assumes a linear trend to represent travel patterns between home and unspecified locations.

\subsubsection{Distribution of visitors}

The daily number and seasonal variation of overnight and day-trip visitors to Napier are derived from local and regional tourist data (Ministry of Economic Development, 2013a, b; Statistics New Zealand, 2012b, c). Overnight visitors are distinguished by accommodation type (commercial or private) and distributed to the appropriate building type in nighttime exposure scenarios. Between 23:00-06:00, visitors in private accommodation are distributed in groups of two (mean number of guests per stay night $=1.67$ ) to randomly
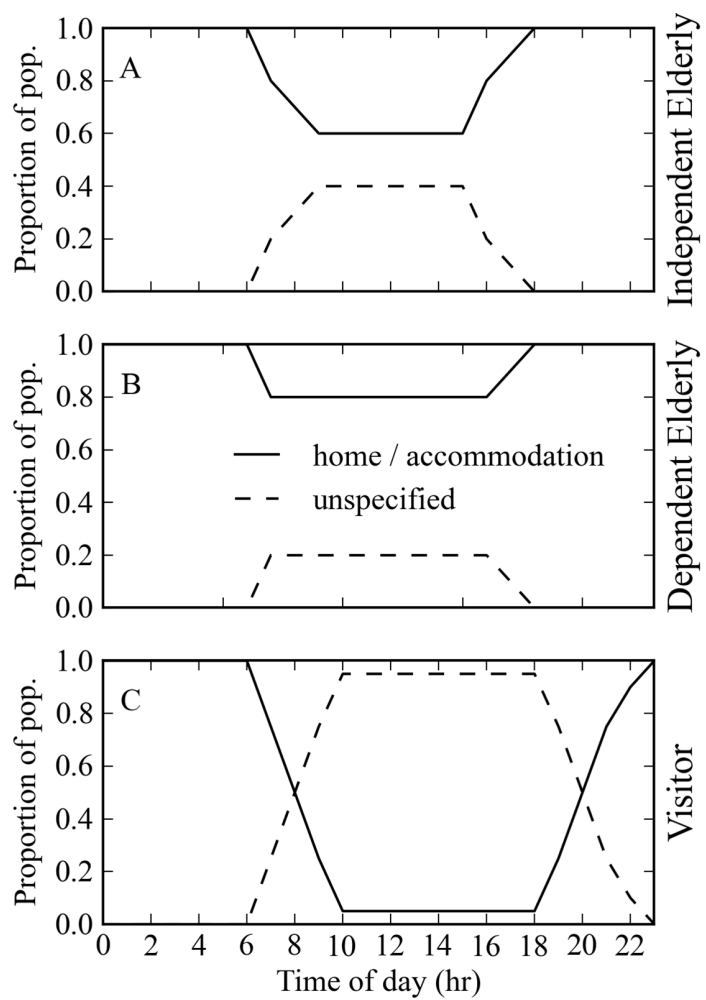

Figure 3. Population-time profiles to distribute visitors (a), independent elderly (b) and dependent elderly (c) to home or accommodation, and unspecified locations. Profiles for these groups are the same for weekdays and weekends.

selected residential buildings in Napier (Fig. 3c). Those in commercial accommodation are distributed in groups of two to randomly selected tourist accommodation (hotel/motel/backpacker/holiday park) according to facility capacity as a proportion of total commercial accommodation capacity. Based on expert judgement, $95 \%$ of visitors are distributed to unspecified locations between 10:00-18:00 using the spatially weighted approach, and $5 \%$ are assumed to be at their accommodation. The estimated number of daytrip visitors is distributed with the spatially weighted random distribution for exposure scenarios between 08:00-20:00.

\subsection{Estimation of evacuation time}

A person's total evacuation time is represented by a series of discrete time components that include event detection, warning transmission and reception, evacuation preparation and evacuation travel (e.g. Urbanik et al., 1980; Post et al., 2009; Purser, 2010; González-Riancho et al., 2013). An evacuation time sequence for an individual or group can be defined as: $\mathrm{ET}_{\mathrm{t}}=\mathrm{EA}_{\mathrm{t}}+\mathrm{AD}_{\mathrm{t}}+\mathrm{WD}_{\mathrm{t}}+\mathrm{ID}_{\mathrm{t}}+\mathrm{EP}_{\mathrm{t}}+\mathrm{TT}_{\mathrm{t}}$ where $\mathrm{E}_{\mathrm{t}}$ is total evacuation time; $\mathrm{EA}_{t}$ is time required to detect an event and assess the threat; $\mathrm{AD}_{\mathrm{t}}$ is authorities' decision-making time for issuing an advisory/warning after a threat assessment; $\mathrm{WD}_{\mathrm{t}}$ is warning dissemination time between the decision 
to issue a warning and warning receipt by the public; $\mathrm{ID}_{\mathrm{t}}$ is individual decision-making time on whether to evacuate or to seek further information; $\mathrm{EP}_{\mathrm{t}}$ is individual preparation time between an evacuation decision and initiating movement; and $\mathrm{TT}_{\mathrm{t}}$ is evacuation travel time that is spent in transit between location at the time of warning and safe destination. An individual is considered to have the potential to evacuate successfully if $\mathrm{ET}_{\mathrm{t}}$ is less than wave arrival time.

In local-source tsunami, short wave arrival times and technological limitations mean that the detection and warning phases may not be completed fast enough to provide warning with sufficient time for the subsequent evacuation phases. Instead, tsunami education encourages immediate evacuation on recognition of natural warnings such as earthquake ground shaking or observations of unusual marine phenomena. Therefore, total evacuation time in the case of localsource tsunami is a function of the time for individuals to recognise a threat and decide to evacuate $\left(\mathrm{ID}_{\mathrm{t}}\right)$, the time it takes them to prepare to evacuate $\left(\mathrm{EP}_{\mathrm{t}}\right)$, and their travel time $\left(\mathrm{TT}_{\mathrm{t}}\right)$ so that: $\mathrm{ET}_{\mathrm{t}}=\mathrm{ID}_{\mathrm{t}}+\mathrm{EP}_{\mathrm{t}}+\mathrm{TT}_{\mathrm{t}}$.

In this proposed method, evacuation preparation time (Sect. 3.3.1) and travel time (Sect. 3.3.2) are estimated separately and summed to yield total evacuation time for each individual $\left(\mathrm{ET}_{\mathrm{t}}\right)$. To account for uncertainty in evacuation time for each exposure scenario, 500 simulations of evacuation time are conducted for each individual in the population to generate mean $\mathrm{ET}_{\mathrm{t}}$. From these 500 simulations, the $95 \%$ confidence interval is less than $2 \%$ of the mean population at $20-30 \mathrm{~min}$, and less than $11 \%$ in the tail of the curve (Fig. 4a, which shows the distribution of population for $\mathrm{ET}_{\mathrm{t}}$ in the range $0-90 \mathrm{~min}$ ). The $95 \%$ confidence interval range based on 1000 simulations is less than 1-7\%. Five hundred simulations were therefore conducted because they provide comparably accurate view of the evacuation time curve for a $50 \%$ reduction in computational expense. Individuals whose mean $\mathrm{ET}_{\mathrm{t}}$ exceeds wave arrival time are subject to further spatial analysis to calculate the population unable to evacuate the hazard zone before wave arrival $\left(P_{\mathrm{VE}}\right)$. $P_{\mathrm{VE}}$ represents the demand for additional evacuation capacity, such as vertical evacuation refuges in the hazard zone.

\subsubsection{Evacuation departure time $\left(\mathrm{ID}_{\mathbf{t}}+\mathbf{E P}_{\mathrm{t}}\right)$}

Modelling evacuation departure time is complex and uncertain. Activities in this phase may include gathering possessions, warning/helping others, confirming warnings, seeking additional information, and re-uniting or making contact with family before evacuating together (Drabek, 1986; Lindell and Perry, 1992, 2012). These types of behaviour have been reported in local-source tsunami (Fraser et al., 2012; Yun and Hamada, 2012), but literature concerning tsunami evacuation behaviour remains relatively limited (Dash and Gladwin, 2007; Lindell and Prater, 2010). Quantitative data available to constrain tsunami evacuation departure to specific time ranges are limited to very few studies (Suzuki and Imamura, 2005; Mas et al., 2012).

Substantial numbers of people choose not to, or are unable to evacuate upon receiving hazard warnings (Lindell and Perry, 1992; Johnston et al., 2005; Lindell et al., 2011; Lindell and Perry, 2012), resulting in a compliance rate much less than $100 \%$. Earthquake ground shaking is often not interpreted by people as a tsunami warning (Gregg et al., 2006), therefore not all people evacuate the hazard zone. Compliance rate is little-studied for local-source tsunami, but may be influenced by proximity to the shoreline, property ownership, age and preparation of household plans (Charnkol and Tanaboriboon, 2006; Murakami and Kashiwabara, 2011). Tsunami evacuation intention surveys in our study area suggest relatively high but location-dependent compliance rate based on a natural warning: $84 \%$ for respondents on the street at the time of an earthquake, $56 \%$ when at home (Fraser et al., 2013). A spatially variable compliance rate is supported in the proposed method but due to the focus on travel speeds in this analysis, compliance rate is assumed to be $100 \%$

Preliminary surveys of intended evacuation behaviour among residents and visitors in Napier were unable to quantify evacuation decision-making and preparation time but confirmed that people's intended actions would delay evacuation (Fraser et al., 2013). Therefore, departure time is represented by a time sampled randomly from a Rayleigh distribution. Sigmoid curves have been previously used to simulate an initially slow rate of increase in the number evacuating, followed by a more rapid rate of evacuation for hurricanes and nuclear accidents (e.g. Tweedie et al., 1986; Lindell et al., 2002; Southworth, 1991). Observed departure times in tsunami events are well correlated with the Rayleigh function (Imamura et al., 2012; Mas et al., 2012). Suzuki and Imamura (2005) estimated that an optimum evacuation curve has a mean value of $7 \mathrm{~min}$, while Mas et al. (2012) proposed that a worst-case curve tends towards arrival time, as people wait until later to evacuate. Following the approach of Mas et al. (2012), Rayleigh curves with mean values of 7 and $38 \mathrm{~min}$ are applied in this analysis as lower and upper bounds potential evacuation-time curves (Fig. 5). For each simulation, a mean departure time value is randomly selected from the range $7-38 \mathrm{~min}$, to generate a new Rayleigh function that falls in the shaded area of Fig. 5. Every individual or group is then assigned an evacuation departure time sampled from the corresponding probability density function. Fraser et al. (2013) suggested different intended actions based on gender and location at the time of earthquake. However, in the absence of quantitative data to inform a relationship between the two, departure time is treated as independent of any demographic characteristics or situational/spatial context. 

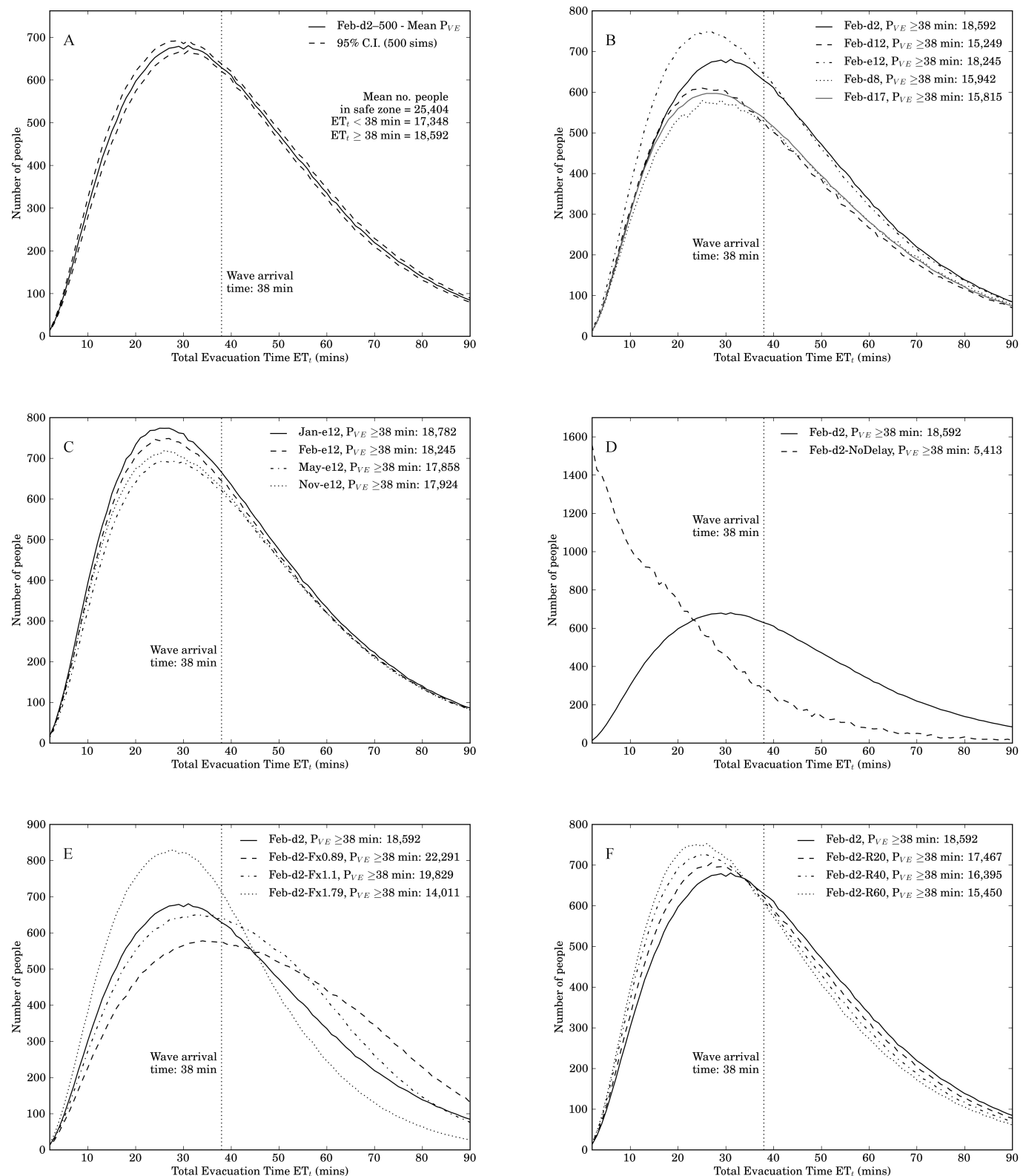

Figure 4. Evacuation time curves in the range 0-90 min, showing wave arrival time and $P_{\mathrm{VE}}$ values for each curve. $P_{\mathrm{VE}}$ represents the demand for additional evacuation capacity, such as vertical evacuation refuges in the hazard zone. (a) Mean $P_{\mathrm{VE}}$ and $95 \%$ confidence intervals based on 500 simulations for the February weekday 02:00 (Feb-d2) exposure scenario; (b) diurnal variation in evacuation time for February weekday (Feb-d*) and weekend (Feb-e*) scenarios; (c) seasonal variation in evacuation time for weekend 12:00 (*-e12) scenario; (d) comparison of evacuation time curves for February weekday 02:00 (Feb-d2) scenario, with and without delayed evacuation departure time; (e) comparison of analysis with distributed travel speeds compared to fixed speeds for February weekday 02:00 (Feb-d2) scenario; and (f) the impact of applying different probabilities that unimpaired adults and children run to evacuate.

\subsubsection{Evacuation travel time $\left(\mathbf{T T}_{\mathbf{t}}\right)$}

Evacuation travel mode, generally pedestrian or vehicular, determines the speed and density at which people can travel through a transport network. Travel mode is influenced by distance to destination (Lamb and Walton, 2011), starting location (Fraser et al., 2013), and local context such as regular transportation modes (Murakami and Kashiwabara, 2011; Okumura et al., 2011). Tsunami education promotes pedestrian evacuation in local-source tsunami to minimise traffic congestion that can slow evacuation. Previous LCD pedestrian evacuation models have used a single walking speed for all evacuees, or used a different speed for each of several 


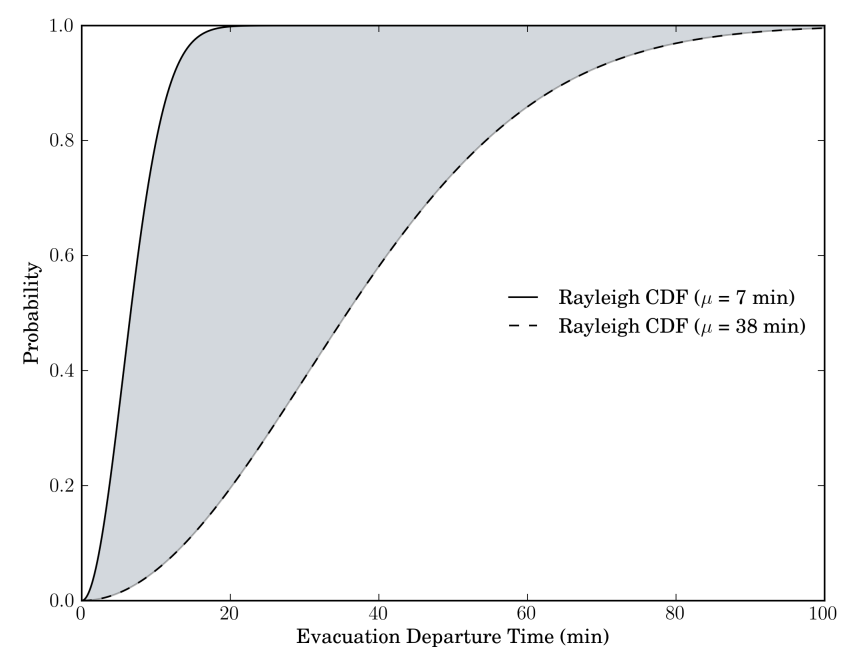

Figure 5. Minimum and maximum bounds of evacuation departure time, represented by Rayleigh functions with $\mu=7 \mathrm{~min}$ and $\mu=38 \mathrm{~min}$. In each simulation, mean evacuation departure time is sampled from the range 7-38 min, and a new Rayleigh function generated. Each individual's evacuation departure time is then sampled from that curve, which falls in the shaded area.

demographic groups, representing the impact of age and relative mobility (Table 1).

Variability in travel speed is included in this study by sampling from a speed distribution that is developed using previously published speeds. To assign distributed travel speeds to the modelled population, walking speeds identified in the literature are grouped into one of five travel speed groups: Elderly, Child, Adult impaired, Adult unimpaired, and Running (Table 1). The five travel speed groups are based on the categories given in the originating studies. The travel speeds found in the literature range between 0.21 and $3.83 \mathrm{~m} \mathrm{~s}^{-1}$. There is a range of $1.92 \mathrm{~m} \mathrm{~s}^{-1}$ in the adult unimpaired group, $1.54 \mathrm{~m} \mathrm{~s}^{-1}$ for children, and $1.09 \mathrm{~m} \mathrm{~s}^{-1}$ for elderly. These ranges represent variability in walking speeds that has not been captured by previous studies that apply a fixed speed to each category.

The mean speed and standard deviation for each travel speed group (Table 2) are used to generate normal distributions of travel speed (Fig. 6). For each individual, a new travel speed is sampled from the corresponding travel speed distribution in each of the 500 simulations. The inverse of sampled travel speed is multiplied by the least-cost path distance value at the individual's location, to calculate travel time to safety $\left(\mathrm{TT}_{\mathrm{t}}\right)$.

Whilst 65 years (the nominal retirement age in New Zealand) is used in this modelling as a threshold to consider people as non-working, this is arbitrary as a threshold for implementing slower evacuation speeds. Assigning a very slow travel speed to everyone above 65 years is unwarranted, as deterioration in mobility is gradual and highly variable. Therefore, different minimum-age thresholds $(65$,

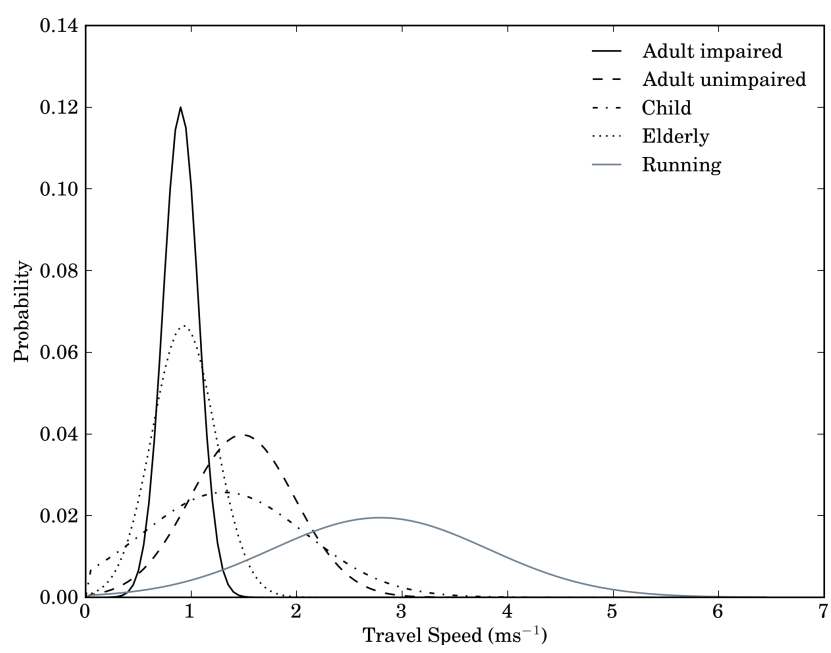

Figure 6. Normally distributed travel speed for each population group based on statistics presented in Table 2. Distributions are derived from the range of travel speeds identified for different groups in the evacuation literature (Table 1).

$70,75,80$ and 85 years) for assigning the elderly travel speed are tested in this analysis.

The proposed method for allocating travel speeds allows for the definition of a probability that an unimpaired adult or child will run in the evacuation, reducing their travel time. The probability of any child or unimpaired adult running is set to 20, 40 and $60 \%$ in three tests. For each child or unimpaired adult in the exposure model, a randomly sampled value between 0 and 1 determines whether that individual is assigned to the running travel speed group, or to their original travel speed group. The proportion of individuals and groups who might run rather than walk in an evacuation is not empirically known. To minimise this uncertainty when investigating temporally variable exposure, running speeds are omitted from the diurnal and seasonal scenarios. This also makes the travel speed model more conservative. Sensitivity tests are conducted during this analysis to test the impact of people running on evacuation potential (Sect. 4.4).

\section{Results}

The results of this analysis are presented in the form of two products that would be intended to provide emergency management personnel with the spatio-temporal view of evacuation success required for effective evacuation planning. The first product, a set of evacuation time curves (Fig. 4), demonstrates the distribution of the population with evacuation time from zero (no evacuation required) to the upper limit of evacuation time. These curves enable emergency managers to make quick assessment of the total population unable to evacuate in different scenarios, facilitating comparison of proposed evacuation routing options, the effect 
Table 1. Pedestrian travel speeds used in previous evacuation analyses; these speeds are used in this study to generate travel speed distributions. Sources - 1: FEMA (2008); 2: Wood and Schmidtlein (2012); 3: Cabinet Office Government of Japan (2005); 4: Yagi and Hasemi (2010); 5: Chooramun et al. (2012); 6: Revi and Singh (2006); 7: Knoblauch et al. (1996); 8: Park et al. (2012); 9: Liu et al. (2009); 10: Johnstone (2012); 11: Liu et al. (2006); 12: Goto et al. (2012); 13: Sugimoto et al. (2003); 14: Post et al. (2009); 15: Mas et al. (2012).

\begin{tabular}{|c|c|c|c|c|}
\hline Source & Original description & $\begin{array}{l}\text { Assigned travel } \\
\text { speed group }\end{array}$ & Travel speed $\mathrm{m} \mathrm{s}^{-1}$ & $\begin{array}{l}\text { Max. distance }(\mathrm{km}) \text { in } \\
38 \text { min }\end{array}$ \\
\hline \multirow[t]{2}{*}{1} & Mobility impaired & Adult impaired & 0.89 & 2.04 \\
\hline & Non mobility impaired & Adult unimpaired & 1.79 & 4.08 \\
\hline \multirow[t]{3}{*}{2} & Running - fast, moderate, slow & Running & $3.83,2.68,1.79$ & $8.73,6.11,4.08$ \\
\hline & Walking - fast, moderate, slow & Adult unimpaired & $1.52,1.22,0.91$ & $3.47,2.78,2.07$ \\
\hline & Walking - US crosswalk standards & Adult unimpaired & 1.10 & 2.60 \\
\hline \multirow[t]{4}{*}{3} & Walking: old man alone & Elderly & 1.30 & 2.96 \\
\hline & Walking: crowd, "sighted" & Adult unimpaired & $0.88,1.29$ & $2.01,2.94$ \\
\hline & Walking: people with disability & Adult impaired & 0.91 & 2.07 \\
\hline & Walking up stairs: old man & Elderly & 0.21 & 0.48 \\
\hline \multirow[t]{2}{*}{4} & Walking (horizontal) & Adult unimpaired & 1.00 & 2.28 \\
\hline & Walking (up stairs) & Adult impaired & 0.58 & 1.32 \\
\hline 5 & Unimpaired walking speed & Adult unimpaired & 1.50 & 3.42 \\
\hline \multirow[t]{3}{*}{6} & Adult mean walking speed & Adult unimpaired & 1.39 & 3.17 \\
\hline & Older person mean walking speed & Elderly & 1.11 & 2.53 \\
\hline & Children mean walking speed & Child & 0.56 & 1.27 \\
\hline \multirow[t]{2}{*}{7} & Younger person (14-64) design speed, 15th \%ile & Adult unimpaired & $1.22,1.25$ & $2.78,2.85$ \\
\hline & Older person $(65+)$ design speed, 15 th $\%$ ile & Elderly & $0.91,0.97$ & $2.07,2.21$ \\
\hline \multirow[t]{2}{*}{8} & Age $65+$ & Elderly & 1.25 & 2.86 \\
\hline & Age 13-64 & Adult unimpaired & 1.51 & 3.44 \\
\hline \multirow[t]{3}{*}{9} & Age $6-17$ & Child & 1.20 & 2.74 \\
\hline & Age 18-69 & Adult unimpaired & 1.40 & 3.19 \\
\hline & Age $70+$ & Elderly & 1.00 & 2.28 \\
\hline 10 & All & Adult unimpaired & 1.25 & 3.00 \\
\hline \multirow[t]{2}{*}{11} & Young walking & Adult unimpaired & 1.10 & 2.51 \\
\hline & Old walking & Elderly & 0.80 & 1.82 \\
\hline \multirow[t]{2}{*}{12} & Normal walkers max speed & Adult unimpaired & 1.50 & 3.42 \\
\hline & Slow walkers max speed & Adult impaired & 0.75 & 1.71 \\
\hline \multirow[t]{2}{*}{13} & Person: pushing a perambulator, with a child & Adult impaired & $1.07,1.02$ & $2.44,2.33$ \\
\hline & Walking elderly person: independent, group & Elderly & $0.95,0.75$ & $2.16,1.71$ \\
\hline \multirow[t]{3}{*}{14} & Age 15-62: male, female & Adult unimpaired & $2.80,2.70$ & $6.38,6.16$ \\
\hline & Age $<14$ & Child & 2.10 & 4.79 \\
\hline & Age $>62$ & Elderly & 0.70 & 1.60 \\
\hline 15 & All - maximum walking speed & Adult unimpaired & 1.33 & 3.03 \\
\hline
\end{tabular}

of introducing vertical evacuation facilities, and comparison of evacuation in different exposure scenarios. They also enable a rapid assessment of the evacuation potential in inundation scenarios for which tsunami arrival has been estimated, which can provide benefit in actual events rather than planning situations. The second product - maps showing density of populations who cannot evacuate successfully (e.g. Fig. 7) - demonstrates the spatial density of population who cannot evacuate in time. These maps can help emergency managers to prioritise areas in which to improve evacuation potential and increase preparedness, but can also provide decision support in real time, in terms of directing emergency response personnel to rescue people in an event, ahead of tsunami arrival. 

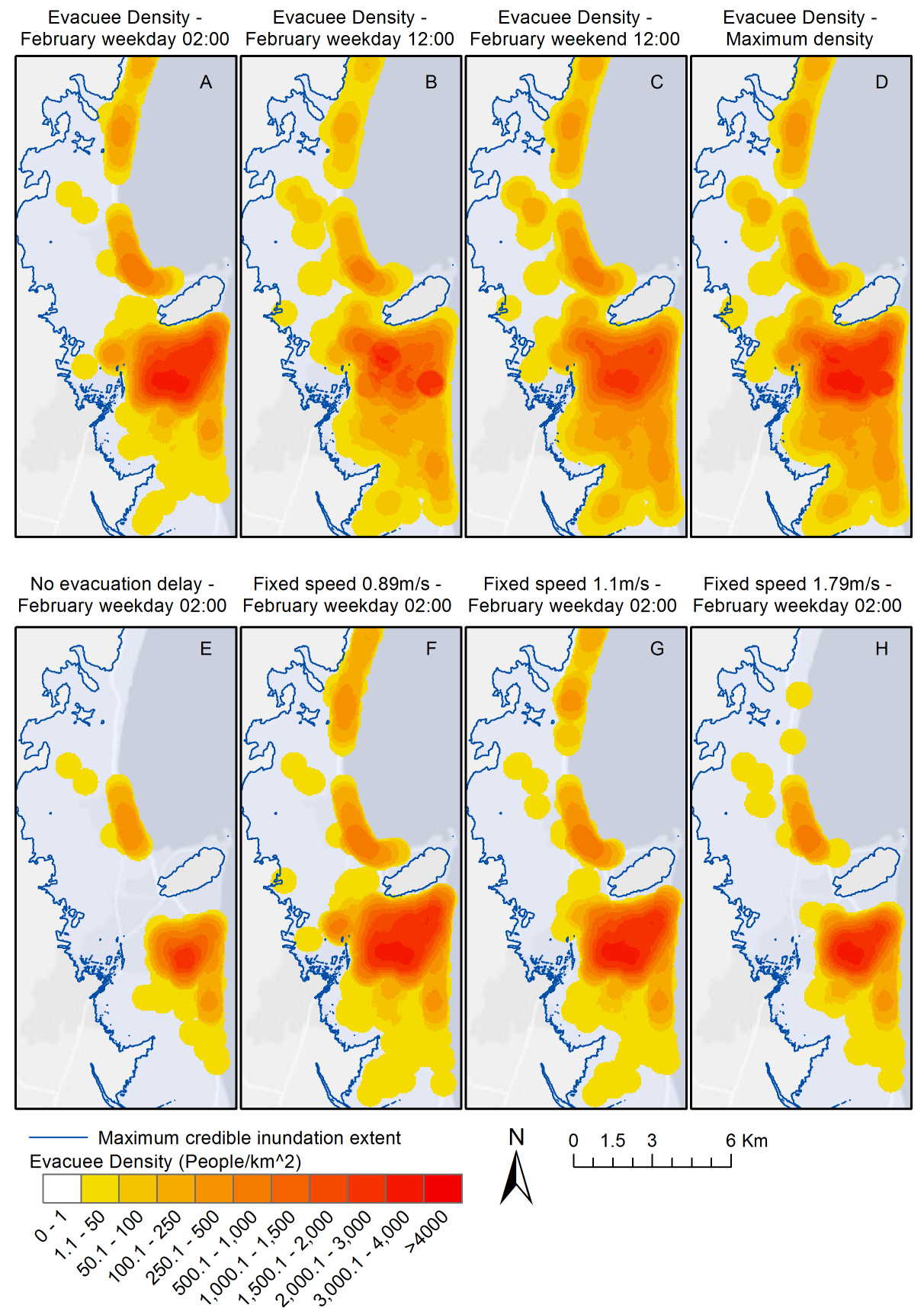

Figure 7. Point density maps showing the density of population with an evacuation time greater than wave arrival time $P_{\mathrm{VE}}$. Generated using the distributed travel speed approach, these maps indicate the variation due to diurnal changes in population distribution. (a) February weekday 02:00; (b) February weekday 12:00; (c) February weekend 12:00; (d) maximum density from all tested exposure scenarios; (e) February weekday 02:00 with evacuation delay omitted (evacuation travel time only); (f) February weekday 02:00 using fixed speed of 0.89 $\mathrm{m} \mathrm{s}^{-1}$; (g) February weekday 02:00 using fixed speed of $1.1 \mathrm{~m} \mathrm{~s}^{-1}$; (h) February weekday 02:00 using fixed speed of $1.79 \mathrm{~m} \mathrm{~s}^{-1}$.

\subsection{Spatio-temporal variation in evacuation demand}

The results reported in this section use consistent assumptions to demonstrate the influence of exposure changes: 38 min wave arrival time, elderly age threshold of 80 years (Sect. 3.2.4), and $100 \%$ compliance rate.
Total population in each scenario ranges between $92 \%$ of URP for a weekday 17:00 scenario, and $110 \%$ on a weekend at 12:00. The 17:00 scenario omits non-resident schoolchildren and resident (outgoing) commuters, who are assumed to be outside the study area at that time. The weekend 12:00 scenario has a high population because it includes 
Table 2. Travel speed statistics $\left(\mathrm{m} \mathrm{s}^{-1}\right)$ for each travel speed group, compiled from travel speeds in the literature (Table 1).

\begin{tabular}{llllll}
\hline & $\begin{array}{l}\text { Adult } \\
\text { impaired }\end{array}$ & $\begin{array}{l}\text { Adult } \\
\text { unimpaired }\end{array}$ & Child & Elderly & Running \\
\hline$n$ & 6 & 20 & 3 & 11 & 3 \\
Min & 0.58 & 0.88 & 0.56 & 0.21 & 1.79 \\
Max & 1.07 & 2.80 & 2.10 & 1.30 & 3.83 \\
Mean & 0.87 & 1.43 & 1.29 & 0.90 & 2.77 \\
SD & 0.18 & 0.50 & 0.78 & 0.30 & 1.02 \\
\hline
\end{tabular}

resident commuters and an additional 4000 day-trip visitors. There is substantial diurnal variation in exposure distribution on weekdays. Individual suburbs show population change of -55 to $150 \%$ when comparing exposure at 02:00 to exposure at 12:00, as residential population is re-distributed to schools and commercial/industrial areas during the day. Variation between suburbs is also significant when comparing weekday and weekend exposure ( -54 to $75 \%$ ), but seasonal variation in all suburbs is relatively limited (generally $<11 \%$ ).

For this case study, there is some diurnal variation in $P_{\mathrm{VE}}$ (Fig. 4b) but little seasonal variation (Fig. 4c). It is estimated that $15200-18800$ people (25-30\% of the total population) are unable to evacuate before wave arrival at $38 \mathrm{~min}$ and require additional evacuation options. Highest $P_{\mathrm{VE}} \mathrm{Oc}-$ curs on a weekday at 02:00 (29-30\%) and weekend at 12:00 (28-29\%). The weekday 12:00 scenario shows the lowest $P_{\mathrm{VE}}(25-26 \%)$. Peak commuting scenarios have $P_{\mathrm{VE}}$ of $26 \%$ for $08: 00$ and $29 \%$ for 17:00.

Although absolute $P_{\mathrm{VE}}$ shows minor fluctuations (5\% of the total population) between each exposure scenario, this masks the significant localised variation in $P_{\mathrm{VE}}$ at suburb level between exposure scenarios (Fig. 7a-c). The darker shades in Fig. 7 indicate high concentrations of $P_{\mathrm{VE}}$. These locations have the greatest requirement for additional evacuation capacity and could potentially have the highest number of casualties or people trapped in a tsunami. The 02:00 scenario shows a large area of peak $P_{\mathrm{VE}}$ density in the residential suburbs, which have high concentrations of URP at residential locations overnight. $P_{\mathrm{VE}}$ on a weekday at 12:00 is strongly influenced by the large population concentrations at several schools, which show as two distinct areas of peak density. Otherwise, the $P_{\mathrm{VE}}$ density evident at 02:00 is more evenly distributed in the 12:00 scenario.

Maximum $P_{\mathrm{VE}}$ density occurs in a weekday 02:00 scenario (2800 people $\mathrm{km}^{-2}$ ) and is $33-41 \%$ lower for all other scenarios. In the weekend 12:00 scenarios, a smaller proportion of the city has high $P_{\mathrm{VE}}$ density (greater than 1500 people $\mathrm{km}^{-2}$ ) compared to weekday 02:00. However, density increases along the coastline and commercial-use areas in weekend day-time scenarios, to a moderate $P_{\mathrm{VE}}$ density of 200-1000 people $\mathrm{km}^{-2}$. $P_{\mathrm{VE}}$ in the top three suburbs (in terms of $P_{\mathrm{VE}}$ at 02:00) decreases in all diurnal comparison scenarios compared to a weekday 02:00. These decreases are of the order of 29-52\% (1000-1900 people). Conversely, other suburbs show increases of up to 1600 people $(500 \%)$.

It is important to represent the local variation in $P_{\mathrm{VE}}$ and influence of the weekend/peak-commute scenarios to inform appropriate siting choices when planning evacuation. Multiple exposure scenarios can be combined into a maximum exposure surface for a single analysis to provide maximum potential $P_{\mathrm{VE}}$ at every location (Fig. 7d). Maximum $P_{\mathrm{VE}}$ occurs at weekday 02:00 for seven of the 14 suburbs in the study area. The other $50 \%$ of suburbs experience their maximum $P_{\mathrm{VE}}$ at weekday 08:00 or at weekend 12:00. Therefore, consideration of only the weekday 02:00 and weekday 12:00 scenarios (i.e. night-time and day-time using employment records) would not, for this study location, accurately represent the maximum $P_{\mathrm{VE}}$.

In addition to changes in $P_{\mathrm{VE}}$ distribution, composition of $P_{\mathrm{VE}}$ also varies between exposure scenarios. In a weekday 02:00 scenario at Napier, $91 \%$ of $P_{\mathrm{VE}}$ are people located at home, so the majority of evacuees will be with their household group. At 12:00 on a weekday the distribution is more diverse, posing different challenges for evacuation and emergency response than a night-time scenario. Twenty-five percent of the population are at home, $31 \%$ are children at school, $20 \%$ are people at work, and $21 \%$ are tourists, resident adults and elderly people at unspecified locations. In these scenarios, evacuation of large groups becomes more prevalent and immediate actions are likely to include connecting with family and travelling to schools before evacuating. At 12:00 on a weekend, $P_{\mathrm{VE}}$ comprises $47 \%$ at home, $14 \%$ work and $31 \%$ of people at unspecified locations (an equal composition of resident adults, children, and tourists). One of the most vulnerable groups, people in elderly care facilities, comprises $<1 \%$ of $P_{\mathrm{VE}}(<200$ people) in each scenario.

\subsection{Evacuation departure time}

To demonstrate the importance of including evacuation departure time in evacuation modelling, analysis was conducted with the decision-making and preparation time phases $\left(\mathrm{ID}_{\mathrm{t}}+\mathrm{EP}_{\mathrm{t}}\right)$ omitted. When evacuation departure time is omitted, in a February 02:00 scenario, $\mathrm{ET}_{\mathrm{t}}$ is reduced by $15 \mathrm{~min}$ on average, reducing $P_{\mathrm{VE}}$ from $30 \%$ of total population to $9 \%$. This represents a reduction of 11800 people who require additional evacuation capacity (Figs. $4 \mathrm{~d}$ and $7 \mathrm{e}$ ). Without evacuation departure time, $>50 \%$ of the population have $\mathrm{ET}_{\mathrm{t}}<10 \mathrm{~min}$ and several suburbs show no requirement for additional evacuation capacity. This represents a significant possibility for under-estimating $P_{\mathrm{VE}}$ and requirements for additional evacuation capacity, reinforcing the need to adequately account for the pre-travel phases of evacuation in LCD modelling. Positively, it also demonstrates 
the significant reduction in $\mathrm{ET}_{\mathrm{t}}$ that can be achieved through minimising evacuation delays.

\subsection{Impact of distributed travel speed}

The impact of simulating evacuation with distributed travel speeds in a LCD framework has been tested against three fixed travel speeds: $0.89,1.1$ and $1.79 \mathrm{~m} \mathrm{~s}^{-1}$. These represent fixed speeds for a mobility-impaired adult (FEMA, 2008), unimpaired adult based on US crosswalk standards (Wood and Schmidtlein, 2012), and an unimpaired adult (FEMA, 2008) (Table 1).

The use of fixed speeds can produce comparable results to distributed travel speeds. This is dependent on the fixed speed corresponding with the mean of travel speed distributions. In this case study, a fixed speed of $0.89 \mathrm{~m} \mathrm{~s}^{-1}$ estimates that $37 \%$ of the exposed population cannot evacuate in time. Simulation with $1.1 \mathrm{~m} \mathrm{~s}^{-1}$ estimates $33 \%$, and $1.79 \mathrm{~m} \mathrm{~s}^{-1}$ estimates $23 \%$. This compares to $38 \%$ for analysis with distributed travel speeds. This corresponds to a $P_{\mathrm{VE}}$ range of 4600 people across the three fixed speed estimates, which is a significant variation in the estimate of required additional evacuation capacity. The use of $1.1 \mathrm{~m} \mathrm{~s}^{-1}$ provides a reasonable assumption to estimate total $P_{\mathrm{VE}}$ where travel speed distributions cannot be modelled (Fig. 4e). However, the $1.1 \mathrm{~m} \mathrm{~s}^{-1}$ fixed speed curve results in a greater number of people with $\mathrm{ET}_{\mathrm{t}}$ of 38-80 min than a distributed speed analysis, which contains more people with $\mathrm{ET}_{\mathrm{t}}>90 \mathrm{~min}$. Therefore, $P_{\mathrm{VE}}$ is more sensitive to changes in evacuation time when a fixed speed of $1.1 \mathrm{~m} \mathrm{~s}^{-1}$ is used. If this fixed speed is used to assess the impact of education to reduce evacuation delays, it is likely to show greater reductions in evacuation demand than analyses with distributed speed. A fixed speed of $0.89 \mathrm{~m} \mathrm{~s}^{-1}$ provides a conservative estimate of $P_{\mathrm{VE}}$, which is generally desirable for evacuation planning, but is less suitable for estimating evacuation demand when designing evacuation refuge capacity and informing investment decisions. A fixed speed of $1.79 \mathrm{~m} \mathrm{~s}^{-1}$ underestimates $P_{\mathrm{VE}}$ compared to the distributed speed approach.

The application of fixed speeds also affects spatial distribution of $P_{\mathrm{VE}}$, which can influence casualty estimation and decisions on where to site evacuation refuges. The first locations to be affected by altering travel speed are those located closest to the safety zone, because a small change in travel speed determines whether $\mathrm{ET}_{\mathrm{t}}$ exceeds wave arrival time or not. Distribution of $P_{\mathrm{VE}}$ density for a fixed speed of $0.89 \mathrm{~m} \mathrm{~s}^{-1}$ corresponds closely to that of the distributed speed analysis, although the extent of high density $\left(>1500\right.$ people $\left.\mathrm{km}^{2}\right)$ is greater than for distributed speeds (Fig. 7f). At $1.1 \mathrm{~m} \mathrm{~s}^{-1}$, the spatial extent of high density begins to reduce, with no reduction in peak $P_{\mathrm{VE}}$ density (Fig. 7g). For $1.79 \mathrm{~m} \mathrm{~s}^{-1}$ several suburbs are estimated to have no requirement for additional evacuation capacity (Fig. 7h); use of this speed could lead to locations that require vertical evacuation being overlooked in decisionmaking processes.

Due to the similarity of mean travel speed in the distributions compiled for elderly and impaired adults (Fig. 6), application of different minimum-age thresholds $(65,70,75$, 80 and 85 years) for the elderly travel speed causes less than $1 \%$ variation in population unable to evacuate before wave arrival. In their current form, and for this exposure case study, the two current travel speed distributions could be combined with minimal impact on results, but in order to demonstrate the functionality of the proposed method, both curves were retained in this study. In other case studies, a proportionally larger elderly population, or concentrations of elderly populations in areas with great travel distances may result in this group having a larger impact. Improved data on evacuation walking speeds of the elderly, and age-related decline in walking speeds, would enable validation and adjustment of this threshold if required.

\subsection{Application of running speeds}

The proposed method enables application of faster travel speeds to proportions of unimpaired adults or children, to test the effect on $P_{\mathrm{VE}}$ of the probability that people may run to evacuate. In three different tests, probability of an unimpaired adult or child being assigned a travel speed sampled from the Running speed distribution (Fig. 6) is set to 20, 40 and $60 \%$. With a $20 \%$ probability of running, $P_{\mathrm{VE}}$ is reduced by $6 \%$. A $12 \%$ decrease in $P_{\mathrm{VE}}$ is achieved with $40 \%$ probability and $17 \%$ reduction with a $60 \%$ probability (Fig. 4f). These results show the tangible impact (reduction in number of casualties) that is possible due to an increase in travel speeds, and demonstrates the utility of this method in testing the impact of faster evacuation due to education and evacuation training. This approach could also be used to quantify the potential benefits of increased bicycle use in evacuations, to determine whether it is worthwhile trying to increase the use of bicycles in evacuation.

\section{Conclusions}

This study has proposed a method that augments a GIS-based least-cost distance evacuation model, to account for temporally variable exposure, uncertain departure time and variability in pedestrian travel speeds. Population-time profiles are developed to provide exposure distributions for several population groups for any month, day or time. A Rayleigh function is applied to account for uncertain evacuation departure time. A review of pedestrian evacuation models shows that a wide range of travel speeds have been applied as one or several fixed speeds in previous analyses. It is postulated that this is not representative of natural variability in pedestrian travel speeds of a population. Previously used travel speeds 
are collated into travel speed distributions for different population groups based on age and relative mobility.

Modelling multiple exposure scenarios facilitates visualisation of the temporal dimension, in addition to spatial distribution, of evacuation demand. This enables emergency managers and planners to understand how the time of an event can affect hazard exposure and potential casualties. Pre-calculated $P_{\mathrm{VE}}$ maps and statistics, derived from a large enough range of exposure scenarios, could assist in: realtime decision making to expedite emergency response to areas with greatest $P_{\mathrm{VE}}$; casualty estimation; public education; and evacuation planning. Robust evacuation planning requires knowledge of maximum potential $P_{\mathrm{VE}}$ at any location to ensure that routes and refuges have sufficient capacity in any event. Whilst this approach displays several benefits, the large amount of detailed data required to develop a detailed temporally variable exposure model poses a significant challenge to its wider application.

In this case study location, $P_{\mathrm{VE}}$ varies little due to diurnal changes in exposure; however, significant temporal variations in $P_{\mathrm{VE}}$ are apparent when comparing individual suburbs. A typical analysis using two scenarios (day-time/nighttime) has the potential to overlook the full range of diurnal variation in evacuation demand, particularly in areas that have large exposure of transitional populations at peak commuting times and on weekends. Seasonal variation is found to be less important for this case study but should not be ruled out for other locations with a higher ratio of visitors to residents. Maximum potential $P_{\mathrm{VE}}$ can be calculated in a single $\mathrm{ET}_{\mathrm{t}}$ analysis, but the estimation of maximum exposure should be based on multiple exposure scenarios, including peak commuting hours and weekends, rather than just two scenarios covering night-time and day-time.

Development of population-time profiles for Napier required several assumptions due to the limited amount of data on diurnal activity patterns in New Zealand and internationally. There remains some disparity in diurnal patterns between the population-time profiles developed for this study and those determined from large samples in the US and Canada. The improvement of diurnal activity data and temporally variable exposure data sets would benefit future risk assessments and evacuation modelling for all hazards. This analysis applied 500 simulations of evacuation time to a population distribution that was unchanged in each exposure scenario. Future analyses should aim to use probabilistic exposure distribution in each simulation to better represent uncertainty in exposure.

Results of evacuation modelling are highly sensitive to the travel speeds applied. The use of fixed speeds c. $1.1 \mathrm{~m} \mathrm{~s}^{-1}$ results in $P_{\mathrm{VE}}$ that is consistent with distributed speeds, demonstrating that this demonstrating that this fixed-speed assumption is suitable for use in aggregate analyses. However, the slowest speeds used in previous analyses would over-estimate evacuation demand, and the fastest would significantly under-estimate demand. There is a requirement to constrain travel speeds in community-scale evacuations. Collection of travel speed data for a range of demographic groups in monitored evacuation exercises could improve distributed travel speed models. This is particularly important for schools and other institutions where group dynamics are likely to affect evacuation speeds. Evacuation decisionmaking and travel time are likely to be affected by physical and intellectual disability (omitted in this analysis), and further research should focus on the impact of this on evacuation time.

There are currently insufficient data on the time required to conduct preparation activities, to quantify preparation time according to personal characteristics and situational context. Quantification of departure time according to different preparation activities would benefit evacuation modelling and planning, and enable validation of Rayleigh functions. It has been demonstrated that a reduction in departure time can significantly reduce evacuation time and increase the proportion of the population able to reach safety. It is important that models incorporate departure time, and that reduction of this phase is a central aim of tsunami education.

Finally, the proposed method provides spatio-temporal variation in evacuation demand for the maximum credible local-source tsunami in the case study location. This highlights the locations in which emergency managers should focus on increasing evacuation potential - for example, through installation of vertical evacuation refuges. While this analysis focuses on pedestrian evacuation potential, this represents only one part of a robust evacuation plan. Complementary agent-based evacuation simulation should be used to validate the results of this least-cost distance method and to elaborate on traffic modelling, network capacity issues and evacuee interactions. The potential disruption to evacuation routes, damage to buildings and infrastructure as a result of earthquake ground shaking, and the effect of aftershocks on evacuation should be considered in future analyses.

Acknowledgements. We would like to thank Jim Cousins (GNS Science) for valuable discussion of exposure models; Megan Harris (Hawke's Bay Tourism) for provision of tourism data; Lisa Pearse (Hawke's Bay Civil Defence Emergency Management Group) and Craig Goodier (Hawke's Bay Regional Council) for provision of topography data; Robyn Tuohy (Massey University) for discussion of age-dependent mobility; and Jeanne Jones (USGS) for providing information on application of ArcGIS anisotropic least-cost path distance module. We would also like to thank two anonymous reviewers and Sergio Freire (European Commission - Joint Research Centre (JRC)) for their review comments, which have helped to improve this paper. This research was supported by public research funding from the Government of New Zealand and the US Geological Survey (USGS) Land Change Science Program. Any use of trade, product, or firm names is for descriptive purposes only and does not imply endorsement by the US Government.

Edited by: M. Gonzalez Rodríguez

Reviewed by: two anonymous referees 


\section{References}

Beyer, H.: Geospatial Modelling Environment (Version 0.7.2.0), available at: http://www.spatialecology.com/gme (last access: 8 February 2014), 2012.

Cabinet Office Government of Japan: Guideline for Tsunami Evacuation Buildings, Tsunami evacuation building guideline committee, Government of Japan Cabinet Office, Tokyo, available at: http://www.bousai.go.jp/jishin/tsunami/hinan/hinanbiru.html (last access: 23 March 2014), 2005.

Charnkol, T. and Tanaboriboon, Y.: Evacuee behaviors and factors affecting the tsunami trip generation model: a case study in Phang-Nga, Thailand, J. Adv. Transport, 40, 313-330, doi:10.1002/atr.5670400306, 2006.

Chooramun, N., Lawrence, P. J., and Galea, E. R.: An agent based evacuation model utilising hybrid space discretisation, Safety Sci., 50, 1685-1694, doi:10.1016/j.ssci.2011.12.022, 2012.

Cockings, S., Martin, D., and Leung, S.: Population 24/7: building space-time specific population surface models, in: Proceedings of the GIS Research UK 18th Annual Conference GISRUK 2010, edited by: Haklay, M. M., Morley, J., and Rahemtulla, H., 14-16 April 2010, London, UK, 41-47, 2010.

Cousins, W. J.: RiskScape - development of a default assets model for Hawke's Bay, Science Report 2009/50, GNS Science, Lower Hutt, New Zealand, 2009.

Dash, N. and Gladwin, H.: Evacuation decision making and behavioral responses: individual and household, Nat. Hazards Rev., 8, 69-77, 2007.

Drabek, T.: Human System Responses to Disaster: an inventory of Sociological Findings, Springer Verlag, New York, 1986.

FEMA: Guidelines for Design of Structures for Vertical Evacuation from Tsunamis, FEMA Report P646, Prepared by the Applied Technology Council for the Federal Emergency Management Agency, Redwood City, California, 2008.

Fraser, S. A., Leonard, G. S., Murakami, H., and Matsuo, I.: Tsunami vertical evacuation buildings - lessons for international preparedness following the 2011 great east Japan tsunami, J. Disaster Res., 7, 446-457, 2012.

Fraser, S. A., Johnston, D. M., and Leonard, G. S.: Intended evacuation behaviour in a local earthquake and tsunami at Napier, New Zealand, Science Report 2013/26, GNS Science, Lower Hutt, New Zealand, 2013.

Fraser, S. A., Power, W. L., Wang, X., Wallace, L. M., Mueller, C., and Johnston, D. M.: Tsunami inundation in Napier, New Zealand, due to local earthquake sources, Nat. Hazards, 70, 415-445, doi:10.1007/s11069-013-0820-x, 2014.

González-Riancho, P., Aguirre-Ayerbe, I., Aniel-Quiroga, I., Abad, S., González, M., Larreynaga, J., Gavidia, F., Gutiérrez, O. Q., Álvarez-Gómez, J. A., and Medina, R.: Tsunami evacuation modelling as a tool for risk reduction: application to the coastal area of El Salvador, Nat. Hazards Earth Syst. Sci., 13, 3249-3270, doi:10.5194/nhess-13-3249-2013, 2013.

Goto, Y., Affan, M., Nurdin, Y., and Yuliana, D. K.: Tsunami evacuation simulation for disaster education and city planning, J. Disaster Res., 7, 92-101, 2012

Graehl, N. and Dengler, L.: Using a GIS to Model Tsunami Evacuation Times for the Community of Fairhaven, California, AGU Fall Meeting Abstracts D1324, San Francisco, California, USA, 2008.
Gregg, C. E., Houghton, B. F., Paton, D., Lachman, R., Lachman, J., Johnston, D. M., and Wongbusarakum, S.: Natural Warning Signs of Tsunamis: Human Sensory Experience and Response to the 2004 Great Sumatra Earthquake and Tsunami in Thailand, Earthq. Spectra, 22, 671-691, doi:10.1193/1.2206791, 2006.

Imamura, F., Muhari, A., Mas, E., Pradono, M. H., Post, J., and Sugimoto, M.: Tsunami disaster mitigation by integrating comprehensive countermeasures in Padang City, Indonesia, Disaster Res., 7, 48-64, 2012.

Johnston, D. M., Paton, D., Crawford, G. L., Ronan, K. R., Houghton, B. F., and Borgelt, P.: Measuring tsunami preparedness in coastal Washington, United States, Nat. Hazards, 35, 173-184, doi:10.1007/s11069-004-2419-8, 2005.

Johnstone, W. M.: Life Safety Modelling Framework and Performance Measures to Assess Community Systems: Application to Tsunami Emergency Preparedness and Dam Safety Management, Ph.D. thesis, University of British Columbia, Vancouver, Canada, 2012.

Klepeis, N. E., Nelson, W. C., Ott, W. R., Robinson, J. P., Tsang, A. M., Switzer, P., Behar, J. V., Hern, S. C., and Engelmann, W. H.: The National Human Activity Pattern Survey (NHAPS): a resource for assessing exposure to environmental pollutants, J. Expo. Anal. Env. Epid., 11, 231-252, doi:10.1038/sj.jea.7500165, 2001.

Knoblauch, R. L., Pietrucha, M. T., and Nitzburg, M.: Field studies of pedestrian walking speed and start-up time, Transport. Res. Rec., 1538, 27-38, doi:10.3141/1538-04, 1996.

Kobayashi, T., Medina, R. M., and Cova, T. J.: Visualizing diurnal population change in urban areas for emergency management, Prof. Geogr., 63, 113-130, doi:10.1080/00330124.2010.533565, 2011.

Lamb, S. M. and Walton, D. K.: Travel behaviours following the 2007 Gisborne earthquake: evidence for the use of simulation in earthquake research, Int. J. Emergency Manage., 8, 42-59, doi:10.1504/IJEM.2011.040397, 2011.

Leech, J. A., Nelson, W. C., Burnett, R. T., Aaron, S., and Raizenne, M. E.: It's about time: a comparison of Canadian and American time-activity patterns, J. Expo. Anal. Env. Epid., 12, 427-432, doi:10.1038/sj.jea.7500244, 2002.

Lindell, M. K. and Perry, R. W.: Behavioral Foundations of Community Emergency Planning, Hemisphere Publishing Corporation, Washington, D.C., USA, 1992.

Lindell, M. K. and Perry, R. W.: The protective action decision model: theoretical modifications and additional evidence, Risk Anal., 32, 616-632, doi:10.1111/j.1539-6924.2011.01647.x, 2012.

Lindell, M. K. and Prater, C. S.: Tsunami Preparedness on the Oregon and Washington Coast: recommendations for research, Nat. Hazards Rev., 11, 69-81, doi:10.1061/(ASCE)15276988(2010)11:2(69), 2010.

Lindell, M. K., Prater, C. S., Perry, R. W., and Wu, J. Y.: EMBLEM: An Empirically Based Large-Scale Evacuation Time Estimate Model, Report, Hazard Reduction \& Recovery Center, Texas A \& M University, College Station, Texas, 2002.

Lindell, M. K., Kang, J. E., and Prater, C. S.: The logistics of household hurricane evacuation, Nat. Hazards, 58, 1093-1109, doi:10.1007/s11069-011-9715-x, 2011. 
Liu, Y., Hatayama, M., and Okada, N.: Development of an Adaptive Evacuation Route Algorithm under Flood Disaster, Annuals of the Disaster Prevention Research Institute., 49, 189-195, 2006.

Liu, Y., Okada, N., Shen, D., and Li, S.: Agent-based flood evacuation simulation of life - threatening conditions using vitae system model, J. Nat. Disaster Sci., 31, 33-41, 2009.

Mas, E., Suppasri, A., Imamura, F., and Koshimura, S.: Agent-based Simulation of the 2011 great east Japan earthquake/tsunami evacuation: an integrated model of tsunami inundation and evacuation, J. Nat. Disaster Sci., 34, 41-57, 2012.

Ministry for the Environment: New Zealand Land Cover Database version 2, available at: https://lris.scinfo.org.nz/ layer/401-lcdb-v33-land-cover-database-version-33/ (last access: 17 March 2012), 2009.

Ministry of Economic Development: International Visitor Survey Online Database, available at: http://www.med. govt.nz/sectors-industries/tourism/tourism-research-data/ international-visitor-survey/online-database (last access: $18 \mathrm{Au}-$ gust 2013), 2013a.

Ministry of Economic Development: Domestic Travel Survey Online Database, available at: http://www.med. govt.nz/sectors-industries/tourism/tourism-research-data/ domestic-tourism/domestic-travel-survey-online-database (last access: 18 August 2013), 2013b.

Ministry of Education: Directory of Schools - as at 01/08/2012, available at: http://www.minedu.govt.nz/Parents/AllAges/ SchoolSearch.aspx (last access: 8 October 2013), 2012a.

Ministry of Education: Early Childhood Education (ECE) Services Listing (updated at 28 September 2012), available at: http://www. minedu.govt.nz/Parents/AllAges/ECEListing.aspx (last access: 8 October 2013), 2012b.

Murakami, H. and Kashiwabara, K.: Travel Means for Tsunami Evacuation in the 2011 Tohoku Pacific Ocean Earthquake Questionnaire Survey in Natori City, in: Proceedings of the Annual Conference of the Institute of Social Safety Science, 29, 11-12 November 2011, Shizuoka, Japan, 67-70, 2011.

Napier City Council: Statistics: Employment, available at: http:// www.napier.govt.nz/our-council/statistics/employment/, last access: 7 November 2013.

Napier Kindergartens: Our Kindergartens, available at: http:// www.napierkindergartens.co.nz/Our+Kindergartens, last access: 3 September 2012.

Okumura, Y., Harada, K., and Kawata, Y.: Evacuation Behavior in the 29 September 2009 Samoa Islands Region Earthquake Tsunami, J. Earthq. Tsunami, 05, 217-229, doi:10.1142/S179343111100108X, 2011.

Park, S., van de Lindt, J. W., Gupta, R., and Cox, D. T.: Method to determine the locations of tsunami vertical evacuation shelters, Nat. Hazards, 63, 891-908, doi:10.1007/s11069-012-01963, 2012.

Post, J., Wegscheider, S., Mück, M., Zosseder, K., Kiefl, R., Steinmetz, T., and Strunz, G.: Assessment of human immediate response capability related to tsunami threats in Indonesia at a sub-national scale, Nat. Hazards Earth Syst. Sci., 9, 1075-1086, doi:10.5194/nhess-9-1075-2009, 2009.

Power, W. L.: Review of Tsunami Hazard in New Zealand (2013 Update), Consultancy Report 2013/131, GNS Science, Lower Hutt, New Zealand, 2013.
Purser, D.: Comparisons of evacuation efficiency and pre-travel activity times in response to a sounder and two different voice alarms messages, in: Pedestrian and Evacuation Dynamics 2008, edited by: Klingsch, W. W. F., Rogsch, C., Schadschneider, A., and Schreckenberg, M., Springer-Verlag, Berlin, Heidelberg, 121-134, 2010.

Revi, A. and Singh, A. K.: Cyclone and storm surge, pedestrian evacuation and emergency response in India, in: Pedestrian and Evacuation Dynamics 2006, 1984, Springer-Verlag, Berlin, Heidelberg, 2006.

Scheer, S. J., Gardi, A., Guillande, R., Eftichidis, G., Varela, V., De Vanssay, B., and Colbeau-Justin, L.: Handbook of Tsunami Evacuation Planning, SCHEMA Specific Targeted Research Project 030963, European Commission Joint Research Centre, Institute for the Protection and Security of the Citizen, Ispra, Italy, doi:10.2788/34292, 2011.

Southworth, F.: Regional Evacuation Modelling: a State-of-the-ArtReview, ORNL/TM 11740, Centre for Transportation Analysis, Oak Ridge National Laboratory, Oak Ridge, Tennessee, USA, 1991.

Statistics New Zealand: 2006 Census Data, available at: http:// www.stats.govt.nz/Census/2006CensusHomePage.aspx (last access: 3 September 2012), 2006.

Statistics New Zealand: Subnational Population Projections: 2006 (base)-2031 (October 2012 update), available at: http://www.stats.govt.nz/browse_for_stats/population/ estimates_and_projections/SubnationalPopulationProjections_ MR0631UpdateOct12.aspx (last access: 24 November 2012), 2012a.

Statistics New Zealand: Territorial Authority (TA) by Total Accommodation: April 2012, available at: http: //www.stats.govt.nz/browse_for_stats/industry_sectors/ accommodation/accommodation-pivot-tables.aspx (last access: 10 August 2012), 2012b.

Statistics New Zealand: Accommodation pivot tables, available at: http://www.stats.govt.nz/browse_for_stats/industry_sectors/ accommodation/accommodation-pivot-tables.aspx (last access: 10 August 2012), 2012c.

Sugimoto, T., Murakami, H., Kozuki, Y., and Nishikawa, K.: A human damage prediction method for tsunami disasters incorporating evacuation activities, Nat. Hazards, 29, 585-600, 2003.

Suzuki, T. and Imamura, F.: Simulation model of the evacuation from a tsunami in consdieration of the resident consciousness and behaviour, Japan Soc. Nat. Disaster Sci., 23, 521-538, 2005.

Tobler, W.: Three presentations on geographical analysis and modelling, Technical Report 93-1, National Center for Geographic Information and Analysis, University of California, Santa Barbara, 1993.

Tweedie, S. W., Rowland, J. R., Walsh, S. J., Rhoten, R. P., and Hagle, P. I.: A methodology for estimating emergency evacuation times, Soc. Sci. J., 23, 189-204, 1986.

Urbanik, T., Desrosiers, A., Lindell, M. K., and Schuller, C.: An Analysis of Techniques for Estimating Evacuation Times for Emergency Planning Zones, NUREG CR-1745, US Nuclear Regulatory Commission, Washington, D.C., 1980.

Wood, N. J. and Schmidtlein, M. C.: Anisotropic path modeling to assess pedestrian-evacuation potential from Cascadiarelated tsunamis in the US Pacific Northwest, Nat. Hazards, 62, 275-300, doi:10.1007/s11069-011-9994-2, 2012. 
Wood, N. J. and Schmidtlein, M. C.: Community variations in population exposure to near-field tsunami hazards as a function of pedestrian travel time to safety, Nat. Hazards, 65, 1603-1628, doi:10.1007/s11069-012-0434-8, 2013.
Yagi, S. and Hasemi, Y.: Requirements and verification methodology for the design performance of tsunami-hinan buildings (temporary tsunami refuge building), J. Disaster Res., 5, 591-600, 2010.

Yun, N.-Y. and Hamada, M.: Evacuation Behaviors in the 2011 Great East Japan Earthquake, J. Disaster Res., 7, 458-467, 2012. 